\title{
Degradação de silagens de capim-elefante contendo subproduto do urucum $^{1}$
}

\author{
Degradation of elephant grass silages with annatto by-product
}

\author{
Aníbal Coutinho do Rêgo ${ }^{2 *}$, Magno José Duarte Cândido ${ }^{3}$, Elzania Sales Pereira ${ }^{3}$, José Valmir Feitosa e $^{4}$ \\ Margareth Maria Teles Rêgo ${ }^{5}$
}

\begin{abstract}
Resumo - Objetivou-se avaliar a degradação in situ da matéria seca, proteína bruta e fibra em detergente neutro de silagens de capim-elefante contendo cinco níveis $(0 ; 4 ; 8 ; 12$ e 16\%, com base na matéria natural da massa ensilada) de inclusão do subproduto do grão do urucum (SGU). O delineamento utilizado foi inteiramente casualizado em parcelas subdivididas, sendo os níveis de adição às parcelas e os tempos de incubação as subparcelas, com quatro repetições. Para a confecção da silagem, foi utilizado capim-elefante cortado aos 70 dias de crescimento e misturado ao subproduto, armazenado em 20 tambores. As amostras foram pré-secas, moídas em moinho, com peneira de $5 \mathrm{~mm}$, colocado $3 \mathrm{~g}$ de amostra em sacos de náilon, para incubação no rúmen por $0 ; 6 ; 48$ e 96 horas em 2 ovinos sem padrão racial definido, machos e castrados. Observou-se um aumento no desaparecimento da MS até o nível 13,37\% de adição de SGU à ensilagem de capim-elefante para 48 horas de incubação. Para a FDN o desaparecimento com 96 horas de incubação aumentou até $16 \%$ de adição. Para o conjunto de parâmetros de degradação estudado, observou-se que o nível de inclusão de $16 \%$ do SGU apresentou maiores valores para a degradabilidade potencial e efetiva das variáveis em questão. A inclusão do subproduto do grão do urucum à ensilagem de capim-elefante resulta em silagens com maior degradabilidade potencial e efetiva.
\end{abstract}

Palavras-chave - Bixa orellana L. Degradabilidade. Ensilagem. Ovinos. Pennisetum purpureum Schum.

\begin{abstract}
To evaluate the dry matter, neutral detergent fiber and crude protein in situ degradation of elephant grass silages with five levels $(0 ; 4 ; 8 ; 12$ and $16 \%$, on a fresh matter basis) of annatto grain by-product (AGBP), this work was carried out. A split-plot design, consisting on the addition levels the plots and the incubation times the sub-plots, with four replicates, was adopted. For the silages making, the elephant grass was cut 70 days-old and mixed to the by-product, in 20 plastic drums. The samples were dried, grid in a bolter of $5 \mathrm{~mm}$ mesh, being used $3 \mathrm{~g}$ of samples in each nylon bag, for incubation in the rumem for 0; 6; 48 e 96 hours; 2 ram without defined breed were used. Was observed increased the disappearance of the DM until the level $13.37 \%$ of addition of (AGBP) the elephant grass silages for the incubation time 48 hours, this level was that presented the most disappearance DM. For the NDF the disappearance increased until $16 \%$ of addition. For the whole of parameters of degradation, was observed that the level of addition of $16 \%$ of (AGBP) presented the most values for the potential and effective degradability of variables in question. The inclusion of the annatto grain by-product for elephant grass silage results in greater potential and effective degradability.
\end{abstract}

Key words - Bixa orellana L. Degradability. Ensiling. Sheep. Pennisetum purpureum Schum.

\footnotetext{
* Autor para correspondência

${ }^{1}$ Recebido para publicação em 19/02/2009; aprovado em 23/06/2010

Parte do trabalho de conclusão de curso do primeiro autor

${ }^{2}$ Programa de Pós-Graduação em Zootecnia da UNESP, Jaboticabal-SP, Brasil, anibalcr@gmail.com

${ }^{3}$ Departamento de Zootecnia, CCA/UFC, Fortaleza-CE, Brasil, mjdcandido@gmail.com, elzaniasp@yahoo.com.br

${ }^{4}$ Universidade Federal do Ceará, Campus do Cariri, Crato-CE, Brasil, Valmir_feitosa@yahoo.com.br

${ }^{5}$ Bolsista de PNPD, UFRN, Rio Grande do Norte, Brasil, margarethmariateles@yahoo.com.br
} 


\section{Introdução}

A estacionalidade da produção de forragem no Nordeste brasileiro tem sido um dos fatores limitantes na produção de ruminantes. Isso deve-se aos baixos índices pluviométricos e à irregularidade na distribuição de chuvas. A baixa qualidade e quantidade de forragem na época seca demandam o uso de práticas de conservação de alimentos produzidos no período chuvoso, como a ensilagem.

Uma das forrageiras para a ensilagem é o capimelefante (Pennisetum purpureum, Schum.), bastante difundido no Nordeste brasileiro, por apresentar fácil implantação, elevada produção de matéria fresca e ser bem adaptado à região. No entanto, Ferrari Júnior e Lavezzo (2001), esta gramínea, na idade em que possui elevado valor nutritivo, apresenta também elevada umidade e reduzidos teores de carboidratos solúveis associados a elevado poder tampão.

O baixo teor de matéria seca da forrageira no processo de ensilagem promove a baixa pressão osmótica, favorecendo o desenvolvimento de bactérias do gênero Clostridium, as quais desdobram açúcares, ácido lático, proteína e aminoácidos a ácido butírico, acético, amônia e gás carbônico, ocorrendo perdas significativas na qualidade da silagem (McDONALD, 1981). Nos últimos anos é crescente o número de pesquisas com inclusão de aditivos ricos em matéria seca na ensilagem de capim (CÂNDIDO et al., 2007; FERREIRA et al., 2004; NEIVA et al., 2006; RÊGO et al., 2010; SÁ et al., 2007).

O urucuzeiro é uma planta nativa das florestas tropicais, cultivadas em poucos países do mundo, notadamente no Brasil, seu maior produtor; é o corante natural atualmente mais comercializado no mundo, com produção de 11.000 t na América Latina (NOGUEIRA; PAIVA, 2000). Os resíduos dos frutos após a extração das sementes servem para alimentação animal, adubo orgânico ou cobertura morta.

De acordo com Nogueira e Paiva (2000), aproximadamente $2.500 \mathrm{t}$ de subproduto do urucum após a extração da bixina são obtidos no Brasil a cada ano, principalmente na região Nordeste, onde quase $97 \%$ do subproduto não é aproveitado. Esse quadro mostra a quantidade de resíduos que podem ser produzidos pelos complexos agroindustriais. O desenvolvimento de alternativas para o aproveitamento dos subprodutos da agroindústria na alimentação animal é de fundamental importância, já que esses são produzidos e disponíveis tanto em época de oferta como em época de escassez de forragem.

$\mathrm{Na}$ avaliação do valor nutritivo de um alimento, como uma silagem, por exemplo, faz-se, inicialmente, a análise proximal, quantificando-se o teor das principais variáveis nutricionais do alimento (SILVA; QUEIROZ, 2002). A fim de se caracterizar melhor o valor nutritivo, pode-se avaliar também o grau de aproveitamento do alimento através de técnicas in vitro, in situ e in vivo.

Dentre as técnicas existentes para a avaliação dos alimentos, a técnica in situ destaca-se por permitir o contato do alimento teste com o ambiente ruminal, embora o alimento não esteja sujeito a todos os eventos digestivos, como mastigação, ruminação e passagem (NOCEK, 1988). No entanto, a determinação do valor in situ permite obter valores mais próximos aos obtidos in vivo (MERTENS, 1993).

O presente trabalho foi conduzido com o objetivo de avaliar a degradação in situ da matéria seca (MS), da fibra em detergente neutro (FDN) e da proteína bruta (PB), de silagens de capim-elefante contendo cinco níveis de inclusão do subproduto grão do urucum.

\section{Material e métodos}

O experimento foi conduzido no Núcleo de Ensino e Estudos em Forragicultura do Departamento de Zootecnia da Universidade Federal do Ceará - NEEF/DZ/CCA/UFC (www.neef.ufc.br), em Fortaleza-CE. As análises químicobromatológicas foram realizadas no Laboratório de Nutrição Animal do Departamento de Zootecnia da Universidade Federal do Ceará.

O delineamento utilizado foi inteiramente (DIC) casualizado em arranjo de parcelas subdivididas, considerando os níveis de adição as parcelas e os tempos de incubação as subparcelas. Foram utilizados como silos experimentais 20 tambores plásticos de 210 L, distribuídos em cinco níveis de inclusão do subproduto do urucum à ensilagem de capim-elefante $(0 ; 4 ; 8 ; 12$ e $16 \%$, com base na matéria natural), cada tratamento com quatro repetições.

O capim-elefante utilizado para confecção das silagens foi cultivado na Fazenda Experimental Vale do Curú - FEVC/CCA/UFC, situada no município de Pentecoste-CE, localizado na latitude 3 $3^{\circ} 51^{\prime} 18^{\prime \prime}$ Sul e longitude 39 $10^{\prime} 19^{\prime \prime}$ Oeste, com clima do tipo BSw'h', semi-árido quente, segundo a classificação de Köeppen, com precipitação média anual de $806,5 \mathrm{~mm}$. O subproduto do grão do urucum foi obtido na empresa Serra Grande LTDA, localizada no município de Sobral - CE, a partir da extração da bixina dos grãos do urucum. O material obtido na indústria foi moído em moinho tipo martelo com peneira de malha $1 \mathrm{~cm}$.

Para a confecção das silagens foi utilizado o capimelefante cortado aos 70 dias de crescimento, processado em máquina picadora e misturada ao subproduto do urucum. 
A adição do subproduto foi feita com base na matéria natural da massa ensilada, sendo que em cada silo foram colocados $126 \mathrm{~kg}$ de matéria fresca, correspondendo a uma densidade de $600 \mathrm{~kg} / \mathrm{m}^{3}$. Passados 30 dias da ensilagem, os silos foram abertos e colhidas amostras que foram submetidas à pré-secagem em estufa de ventilação forçada a $60{ }^{\circ} \mathrm{C}$ por 72 horas, moídas em moinho com peneira de malha de $1 \mathrm{~mm}$ para análise químico-bromatologica e 5 mm para a incubação in situ.

Para o ensaio in situ, foram utilizados dois ovinos machos, sem padrão racial definido, fistulados no rúmen e com peso médio de $45 \mathrm{~kg}$. Os animais foram mantidos em baias individuais, com comedouro, bebedouro e cocho para o fornecimento de mistura mineral. Foi fornecido diariamente ad libitum em dois períodos, manhã e tarde, feno de capim-elefante e concentrado à base de milho e soja. Foram utilizados sacos de náilon de $13 \times 5 \mathrm{~cm}$ com porosidade de $50 \mu \mathrm{m}$, acondicionando-se em cada saco três gramas de amostra, sendo então incubados no rúmen sempre pela manhã durante $0 ; 6 ; 48$ e 96 horas após o fornecimento do alimento. Decorrido o tempo de incubação, os sacos foram retirados do rúmen, lavados manualmente em água corrente até o desaparecimento da coloração turva. Esses foram levados para estufa de ventilação forçada a $60^{\circ} \mathrm{C}$ durante 72 horas. A partir daí, foram realizadas as análises do resíduo da incubação, matéria seca (MS), proteína bruta (PB) e fibra em detergente neutro (FDN), segundo metodologia descrita em Silva e Queiroz (2002).

Para interpretação dos perfis de degradação da matéria seca e da proteína bruta, utilizou-se o modelo assintótico exponencial de primeira ordem, conforme Orskov e McDonald (1979) adaptado por Sampaio (1988).

$\operatorname{Deg}=\mathrm{A}^{-\mathrm{B}^{(-\mathrm{ct})}}$

Onde,

A - corresponde a degradação potencial do material incubado quando o tempo não é um fator limitante;

B - parâmetro sem valor biológico, ou seja, se não houvesse tempo de colonização, ele corresponderia ao total a ser degradado pela ação microbiana;

c - taxa de degradação por ação fermentativa de B;

$\mathrm{t}=$ tempo de incubação no rúmen, em horas.

Uma vez calculados os coeficientes A, B e c, esses foram aplicados à equação proposta por Ørskov e McDonald (1979) para o cálculo da degradabilidade efetiva:

$$
\mathrm{P}=\mathrm{a}+\mathrm{bc} / \mathrm{c}+\mathrm{k}
$$

Onde,
P - degradação ruminal efetiva do componente nutritivo analisado;

$\mathrm{k}$ - taxa de passagem do alimento, assumiu-se uma taxa de passagem da digesta para o duodeno de $2 ; 5$ e $8 \%$ por hora.

Para interpretação dos perfís de degradação da fibra em detergente neutro, utilizou-se o modelo assintótico exponencial decrescente de primeira ordem proposto por Mertens (1993).

$\mathrm{Y}=\mathrm{b}^{(-\mathrm{ct})}+\mathrm{I}$

Onde,

Y - resíduo no tempo t;

b - fração potencialmente degradável;

c - a taxa de degradação;

$\mathrm{t}$ - equivale aos tempos de incubação;

I - a fração não-degradável.

Foi efetuada análise de variância e de regressão nos dados relativos ao desaparecimento da matéria seca, proteína bruta e fibra em detergente neutro. A escolha dos modelos baseou-se na significância dos coeficientes linear e quadrático, por meio do teste $t$ de "Student", aos níveis de 1 e $5 \%$ de probabilidade. Todas as análises, incluindo o estudo de regressão para o desaparecimento, foram realizadas utilizando o programa estatístico SISVAR (FERREIRA, 1999).

\section{Resultados e discussão}

Pode-se observar que, para os tempos de incubação 0 e 6 horas, o desaparecimento da matéria seca teve comportamento quadrático $(\mathrm{P}<0,05)$ com a inclusão do subproduto do grão do urucum à ensilagem de capimelefante (TAB. 1). Já com 48 horas de incubação dos sacos no rúmen, não foi observada diferença estatística $(P>0,05)$ com a variação nas concentrações do subproduto, sendo que, $13,37 \%$ foi a concentração de subproduto que apresentou desaparecimento ótimo da matéria seca para esse tempo. Com 96 horas de incubação, o desaparecimento da matéria seca teve comportamento linear crescente $(\mathrm{P}<0,01)$ com a inclusão do subproduto.

O aumento no desaparecimento da matéria seca para 96 horas de incubação foi de 0,62 pontos percentuais para cada $1 \%$ de inclusão do subproduto do grão do urucum. Rêgo et al. (2009), trabalhando com inclusão do pedúnculo de caju desidratado na ensilagem de capimelefante, observaram comportamento linear crescente para os mesmo tempo de incubação estudado no presente trabalho, 0,64 pontos percentuais para cada $1 \%$ de inclusão do subproduto do caju. 
Tabela 1 - Desaparecimento (\%) da matéria seca (MS), proteína bruta (PB) e fibra em detergente neutro (FDN) de silagens de capimelefante contendo subproduto do grão do urucum (SGU)

\begin{tabular}{|c|c|c|c|c|c|c|c|}
\hline \multirow{2}{*}{ Tempo (horas) } & \multicolumn{5}{|c|}{ Concentrações do subproduto do grão do urucum na ensilagem } & \multirow{2}{*}{ Equação } & \multirow{2}{*}{$\mathrm{R}^{2}$} \\
\hline & $0 \%$ & $4 \%$ & $8 \%$ & $12 \%$ & $16 \%$ & & \\
\hline \multicolumn{8}{|c|}{ Desaparecimento da MS (\%) } \\
\hline 0 & 19,33 & 19,60 & 21,16 & 24,39 & 26,30 & $Y=19,12+0,11 x+0,02 x^{2 *}$ & 97,77 \\
\hline 6 & 22,93 & 28,12 & 29,00 & 29,85 & 30,52 & $Y=23,40+1,07 x-0,04 x^{2 *}$ & 94,55 \\
\hline 48 & 54,82 & 58,59 & 54,59 & 55,56 & 57,48 & ns & - \\
\hline 96 & 55,01 & 60,55 & 61,59 & 62,66 & 66,49 & $Y=56,25+0,62 x^{* *}$ & 91,09 \\
\hline \multicolumn{8}{|c|}{ Desaparecimento da PB (\%) } \\
\hline 0 & 47,27 & 47,12 & 50,85 & 57,60 & 54,26 & $\mathrm{Y}=46,53+0,61 \mathrm{x}^{* *}$ & 72,72 \\
\hline 6 & 47,88 & 47,39 & 51,89 & 63,85 & 58,85 & $\mathrm{Y}=46,41+0,93 \mathrm{x}^{* *}$ & 68,89 \\
\hline 48 & 59,22 & 66,50 & 65,30 & 68,60 & 60,81 & $Y=59,36+1,96 x-0,11 x^{2 *}$ & 80,14 \\
\hline 96 & 63,36 & 67,61 & 70,90 & 76,30 & 74,80 & $\mathrm{Y}=64,28+0,79 \mathrm{x} * *$ & 89,33 \\
\hline \multicolumn{8}{|c|}{ Desaparecimento da FDN (\%) } \\
\hline 0 & 0,00 & 0,00 & 0,00 & 0,00 & 2,44 & ns & - \\
\hline 6 & 7,35 & 9,07 & 8,51 & 8,02 & 8,91 & $\mathrm{~ns}$ & - \\
\hline 48 & 45,19 & 46,34 & 44,34 & 44,49 & 46,54 & ns & - \\
\hline 96 & 45,98 & 50,88 & 52,03 & 51,01 & 55,61 & $Y=47,22+0,48 x^{* *}$ & 79,19 \\
\hline
\end{tabular}

$* 5 \%$ de probabilidade, ${ }^{* *} 1 \%$ de probabilidade, ns $=$ não significativo a $5 \%$ de probabilidade

O desaparecimento da proteína bruta comportouse de forma linear crescente $(\mathrm{P}<0,01)$ para os tempos de incubação 0; 6 e 96 horas, observando-se aumentos de 0,61 a 0,93 pontos percentuais para cada $1 \%$ de inclusão do subproduto do grão do urucum. Para 48 horas de incubação, foi observado efeito quadrático $(\mathrm{P}<0,05)$ para o desaparecimento da proteína bruta, sendo que $8,91 \%$ de inclusão do subproduto do grão do urucum corresponde ao máximo desaparecimento da proteína bruta.

Com relação ao desaparecimento da fibra em detergente neutro das silagens de capim-elefante contendo subproduto do grão do urucum, não foi observada diferença significativa $(P>0,05)$ para os tempos de incubação $0 ; 6$ e 48 horas. No entanto, 96 horas de incubação das silagens no rúmen, observou-se comportamento linear crescente $(\mathrm{P}<0,01)$ com inclusão do subproduto do urucum. Houve aumento de 0,48 pontos percentuais, para cada $1 \%$ de inclusão do subproduto do grão de urucum à ensilagem de capim-elefante. Essa resposta no desaparecimento da fibra apenas com 96 horas de incubação, pode ser explicada pelo maior tempo de exposição da porção fibrosa do alimento ao ambiente ruminal.

Observando os valores da fração solúvel (a) da matéria seca, têm-se aumento com a inclusão do subproduto do grão do urucum, variando de 19,50 a 26,25\% (TAB. 2). Esse aumento na fração solúvel das silagens pode ser atribuído a maior solubilidade do subproduto isolado comparado ao capim-elefante, contribuindo assim para a maior fração solúvel nas silagens com maior concentração de subproduto. Carvalho et al. (2008), observaram o mesmo comportamento para a fração solúvel da matéria seca quando incluiu farelo de cacau a ensilagem de capim-elefante. Chizzotti et al. (2005), avaliando a degradabilidade ruminal da silagem de capim-elefante verificaram valor de $29,3 \%$ de fração (a), sendo esse superior aos do presente trabalho. Valores da fração solúvel da proteína bruta variaram de 47,27 a 57,60\%, inferiores aos observados por Carvalho et al. (2008), ao adicionar farelo de cacau a ensilagem de capim-elefante.

A fração insolúvel potencialmente degradável (B) da matéria seca variou de $40,27 \%$ para a menor concentração de subproduto do grão do urucum a 45,72\% para a maior concentração do subproduto. Já para proteína bruta, observou-se um aumento da fração potencialmente degradável com a inclusão do subproduto do grão do urucum, valores estes inferiores aos verificados por Rêgo et al. (2009), quando adicionaram pedúnculo de caju desidratado a ensilagem de capim-elefante. Para fibra em detergente neutro, observou-se variação de 50,68 a $58,32 \%$ da fração (B), sendo o maior valor correspondente a $16 \%$ de inclusão do subproduto. A taxa de degradação 
Tabela 2 - Parâmetros de degradabilidade ruminal da matéria seca (MS), proteína bruta (PB) e fibra em detergente neutro (FDN) de silagens de capim-elefante (CE) contendo subproduto do grão do urucum (SGU)

\begin{tabular}{|c|c|c|c|c|}
\hline \multirow{2}{*}{ Silagens } & \multicolumn{3}{|c|}{ Parâmetros } & \multirow{2}{*}{$\mathrm{R}^{2}$} \\
\hline & $\mathrm{a}$ & $\mathrm{B}$ & $\mathrm{c}$ & \\
\hline & \multicolumn{3}{|c|}{ Degradabilidade da MS } & \\
\hline $\mathrm{CE}+0 \% \mathrm{SGU}$ & 19,50 & 40,27 & 0,042 & 0,986 \\
\hline $\mathrm{CE}+4 \% \mathrm{SGU}$ & 19,75 & 43,08 & 0,048 & 0,914 \\
\hline $\mathrm{CE}+8 \% \mathrm{SGU}$ & 21,50 & 42,01 & 0,033 & 0,997 \\
\hline $\mathrm{CE}+12 \% \mathrm{SGU}$ & 24,25 & 41,29 & 0,029 & 0,995 \\
\hline \multirow[t]{3}{*}{$\mathrm{CE}+16 \% \mathrm{SGU}$} & 26,25 & 45,72 & 0,024 & 0,998 \\
\hline & $\mathrm{a}$ & $\mathrm{B}$ & $\mathrm{c}$ & \\
\hline & \multicolumn{3}{|c|}{ Degradabilidade da PB } & \\
\hline $\mathrm{CE}+0 \% \mathrm{SGU}$ & 47,27 & 19,86 & 0,020 & 0,948 \\
\hline $\mathrm{CE}+4 \% \mathrm{SGU}$ & 47,13 & 24,02 & 0,035 & 0,963 \\
\hline $\mathrm{CE}+8 \% \mathrm{SGU}$ & 50,86 & 25,19 & 0,018 & 0,952 \\
\hline $\mathrm{CE}+12 \% \mathrm{SGU}$ & 57,60 & 31,38 & 0,008 & 0,890 \\
\hline \multirow[t]{3}{*}{$\mathrm{CE}+16 \% \mathrm{SGU}$} & - & - & - & - \\
\hline & $\mathrm{B}$ & $\mathrm{I}$ & $\mathrm{c}$ & \\
\hline & \multicolumn{3}{|c|}{ Degradabilidade da FDN } & \\
\hline $\mathrm{CE}+0 \% \mathrm{SGU}$ & 50,68 & 51,80 & 0,046 & 0,975 \\
\hline $\mathrm{CE}+4 \% \mathrm{SGU}$ & 55,03 & 47,80 & 0,044 & 0,994 \\
\hline $\mathrm{CE}+8 \% \mathrm{SGU}$ & 56,50 & 46,48 & 0,038 & 0,996 \\
\hline $\mathrm{CE}+12 \% \mathrm{SGU}$ & 54,76 & 46,89 & 0,037 & 0,990 \\
\hline $\mathrm{CE}+16 \% \mathrm{SGU}$ & 58,32 & 40,52 & 0,030 & 0,994 \\
\hline
\end{tabular}

$\mathrm{a}=$ fração solúvel $(\%) ; \mathrm{B}=$ fração insolúvel potencialmente degradável $(\%) ; \mathrm{I}=$ fração indegradável padronizada $(\%)$; $=$ taxa fracional de degradação $\left(\mathrm{h}^{-1}\right) ; \mathrm{R}^{2}=$ coeficiente de determinação

(c) da matéria seca, apresentou maior valor $(0,048)$ para 4\% de inclusão do subproduto, havendo a partir dessa concentração redução na taxa de degradação. Para todos os níveis de inclusão do subproduto do grão de urucum, a taxa de degradação da matéria seca permaneceu dentro da faixa de 2 a $6 \%$ por hora, uma característica de alimentos de boa qualidade (SAMPAIO, 1988).

A fração indegradável (I) tendeu a diminuiu com à inclusão de SGU, atingindo 40,52\% no nível de inclusão de 16\% de SGU. Comportamento semelhante foi observado para a taxa de degradação (c) da fibra em detergente neutro, que diminuiu à medida que aumentou a inclusão do subproduto. O maior valor $(0,046)$ foi observado no nível de inclusão de $0 \%$. Segundo Chesson et al. (1985), a variação na fração (c) é devido à preferência das bactérias ruminais por diferentes tipos de tecidos vegetais. Esta observação é coerente com o fato de que maiores níveis de aditivos podem favorecer ou não a população microbiana no rúmen, responsável pela degradação de carboidratos não estruturais predominantes nas silagens.

Os valores de B, c e I obtidos para fibra em detergente neutro no nível de inclusão de $16 \%$ de SGU, foram de $58,32 \% ; 3,00 \%$ /hora; e 40,52\%, respectivamente, semelhantes aos observados por Malafaia et al. (1998) para FDN da silagem de milho, de 58,4\%; 2,3\%/h; e $43,1 \%$, respectivamente e aos observado por Katsuki et al. (2006) para FDN da silagem de milho, de 57,83\%; 2\%/h; e $36,16 \%$, respectivamente.

A degradação potencial (DP) da matéria seca aumentou com a inclusão de SGU à ensilagem de capimelefante, chegando a 71,18\% no nível de inclusão de $16 \%$ de SGU (TAB. 3). Rezende et al. (2007), ao avaliarem a degradação ruminal da silagem de capim-napier com adição de farelo de batata diversa, observaram valores de DP da matéria seca de 65,95\% no maior nível de inclusão do farelo de batata (20\%), sendo este inferior ao 
obtido no maior nível de inclusão de SGU neste trabalho. Carvalho et al. (2008), ao avaliarem a degradação ruminal da silagem de capim-elefante com inclusão de farelo de cacau, observaram comportamento inverso para DP da matéria seca com a inclusão desse aditivo.

Para a degradabilidade efetiva $(\mathrm{P})$ da matéria seca, pode-se observar um aumento com o nível de inclusão do SGU, atingindo seus valores máximos no nível 16,0\% do subproduto, que variaram de 50,78 a $36,66 \%$ para as taxas de passagem estudadas. A degradabilidade efetiva da matéria seca de $50,78 \%$ para a silagem de capim-elefante com inclusão de $16,0 \%$ de subproduto do grão do urucum foi superior à observada por Rezende et al. (2007) para a silagem com $20,0 \%$ de inclusão de farelo de batata $(48,32 \%)$, e superior à observada para a silagem de sorgo (46,0\%), conforme Martins et al. (1999). Porém, foi inferior ao valor obtido por Martins et al. (1999) para a silagem de milho $(54,8 \%)$. Vilela et al. (1994) estudando a degradabilidade da matéria seca de vários alimentos, observaram valores para a degradação efetiva de silagem de capim-elefante de 31,$0 ; 18,6$ e 13,6\% para as taxas de passagens $2 ; 5$ e $8 \%$ por hora respectivamente.
Comparando a silagem de capim-elefante com $0 \%$ de inclusão de SGU, com o material dos referidos autores, pode-se notar que as degradabilidades efetivas da matéria seca no presente trabalho foram maiores. Isto pode ser explicado em virtude de o material ensilado na presente pesquisa já a partir de $0 \%$ de inclusão de SGU, ou seja, somente a silagem do capim-elefante, apresentar um teor de fibra inferior e maior teor protéico.

A degradabilidade efetiva decresceu à medida que aumentou a taxa de passagem $(\mathrm{k})$ para todos os níveis de adição estudados. Gonçalves et al. (2004), avaliando a degradabilidade ruminal da matéria seca de SGU, observaram valores altos $(62,96 \%$ a uma taxa de passagem de $5 \%$ por hora) para a degradabilidade efetiva, o que justifica o aumento da mesma com o aumento do nível de adição de SGU no presente trabalho, já que o capimelefante apresenta degradabilidade efetiva menor que o subproduto (SILVA et al., 2005). A degradação potencial (DP) da PB aumentou com a elevação nos níveis de inclusão de SGU à ensilagem de capim-elefante, atingindo seu valor máximo $(91,12 \%)$ no nível de adição de $12 \%$. Rezende et al. (2007), ao avaliar a degradação ruminal de

Tabela 3 - Degradabilidade potencial (DP) e efetiva (P) da matéria seca (MS), proteína bruta (PB) e fibra em detergente neutro (FDN) de silagens de capim-elefante (CE) contendo subproduto do grão do urucum (SGU)

\begin{tabular}{|c|c|c|c|c|}
\hline \multirow{3}{*}{ Silagens } & \multirow{3}{*}{ Degradabilidade Potencial (DP) } & \multicolumn{3}{|c|}{ Degradabilidade Efetiva (P) } \\
\hline & & \multicolumn{3}{|c|}{ Taxa de Passagem (\%/ hora) } \\
\hline & & 2 & 5 & 8 \\
\hline & \multicolumn{4}{|c|}{ Matéria Seca (\%) } \\
\hline $\mathrm{CE}+0 \% \mathrm{SGU}$ & 57,46 & 45,16 & 36,74 & 32,46 \\
\hline $\mathrm{CE}+4 \% \mathrm{SGU}$ & 61,88 & 49,26 & 40,09 & 35,25 \\
\hline $\mathrm{CE}+8 \% \mathrm{SGU}$ & 63,28 & 47,38 & 37,90 & 33,46 \\
\hline $\mathrm{CE}+12 \% \mathrm{SGU}$ & 65,36 & 48,64 & 39,43 & 35,29 \\
\hline \multirow[t]{2}{*}{$\mathrm{CE}+16 \% \mathrm{SGU}$} & 71,18 & 50,78 & 40,86 & 36,66 \\
\hline & \multicolumn{4}{|c|}{ Proteína bruta $(\%)$} \\
\hline $\mathrm{CE}+0 \% \mathrm{SGU}$ & 66,43 & 56,85 & 52,75 & 51,10 \\
\hline $\mathrm{CE}+4 \% \mathrm{SGU}$ & 69,42 & 61,24 & 56,23 & 53,84 \\
\hline $\mathrm{CE}+8 \% \mathrm{SGU}$ & 75,36 & 62,60 & 57,45 & 55,44 \\
\hline $\mathrm{CE}+12 \% \mathrm{SGU}$ & 91,12 & 66,92 & 62,07 & 60,54 \\
\hline \multirow[t]{2}{*}{$\mathrm{CE}+16 \% \mathrm{SGU}$} & - & - & - & - \\
\hline & \multicolumn{4}{|c|}{ Fibra em detergente neutro (\%) } \\
\hline $\mathrm{CE}+0 \% \mathrm{SGU}$ & 50,68 & 34,52 & 23,50 & 17,71 \\
\hline $\mathrm{CE}+4 \% \mathrm{SGU}$ & 55,03 & 35,57 & 23,50 & 17,27 \\
\hline $\mathrm{CE}+8 \% \mathrm{SGU}$ & 56,50 & 34,05 & 21,43 & 15,25 \\
\hline $\mathrm{CE}+12 \% \mathrm{SGU}$ & 54,76 & 34,54 & 22,27 & 16,32 \\
\hline $\mathrm{CE}+16 \% \mathrm{SGU}$ & 58,32 & 37,34 & 24,22 & 18,27 \\
\hline
\end{tabular}


silagem de capim-napier com adição de farelo de batata diversa, observaram valores de degradação potencial da PB de 77,60\% no maior nível de inclusão do farelo de batata (20\%), sendo inferior ao obtido no maior nível de inclusão de SGU neste trabalho.

A degradabilidade efetiva (P) da PB aumentou com a elevação nos níveis de inclusão de SGU, atingindo seus valores máximos no nível $12 \%$ de inclusão de SGU, que variaram de 66,92 a $60,54 \%$ para as taxas de passagens estudadas. Martins et al. (1999), avaliando a degradabilidade efetiva da $\mathrm{PB}$ de silagem de milho e de sorgo, observaram valores de 70,40 e $67,9 \%$, respectivamente, os quais foram ligeiramente superiores ao observado para o nível de inclusão de $12 \%$ de SGU. Rezende et al. (2007), estudando a degradação ruminal de silagens de capim-napier com inclusão de farelo da batata, observaram uma degradação efetiva da $\mathrm{PB}$ de $69,02 \%$ para o nível de inclusão $10 \%$, valor esse próximo ao observado para o nível $12 \%$ de inclusão de SGU no presente trabalho.

À medida que a taxa de passagem do alimento no rúmen $(\mathrm{k})$ aumentou, a degradabilidade efetiva da $\mathrm{PB}$ diminuiu para todos os tratamentos. Esses resultados podem ser considerados altos quando comparados com resultados obtidos a partir de incubação de silagem de capim-elefante exclusivo conforme verificado por Valadares Filho (1994).

Os valores de degradação da proteína bruta aqui observados podem ser atribuídos ao menor ou maior incremento de NNP das silagens em decorrência da proteólise durante a fermentação no silo. Sugere-se que a fermentação dentro do silo é responsável pelo aumento da fração solúvel de gramíneas conservadas na forma de silagens (PETIT; TREMBLAY, 1992).

Com relação a degradabilidade efetiva $(\mathrm{P})$ da fibra em detergente neutro, pode-se observar que assim como os demais parâmetros estudados o nível de inclusão de $16 \%$ apresentou os maiores valores, independente das taxas de passagem estudadas, mostrando que para a FDN essa silagem apresenta maior desaparecimento que as demais. A degradabilidade efetiva decresceu à medida que aumentou a taxa de passagem (k) para todos os níveis de adição estudados, esse comportamento é devido ao menor tempo de permanência do alimento no trato digestivo para a ação da microbiota ruminal.

Verificando o conjunto dos parâmetros de degradação (degradabilidade potencial e efetiva) das variáveis (MS, PB e FDN), pode-se observar que houve aumento até $16 \%$ de inclusão do subproduto do grão do urucum. Gonçalves et al. (2006) recomendou a adição de $20 \%$ do subproduto do grão do urucum à ensilagem do capim-elefante com base na melhoria da qualidade e no valor nutritivo da silagem, devendo-se levar em conta que a partir de $12 \%$ de adição do SGU, já se obtém o máximo desaparecimento das frações estudadas.

\section{Conclusão}

A inclusão do subproduto do grão do urucum à ensilagem de capim-elefante resulta em silagens com maior degradabilidade potencial e efetiva, tornando assim, uma alternativa para a alimentação de ruminantes.

\section{Agradecimentos}

Ao Programa de Educação Tutorial, PETAgronomia, pela bolsa concedida ao primeiro autor.

\section{Referências}

CÂNDIDO, M. J. D. et al. Características fermentativas e composição química de silagens de capim-elefante contendo subprodutos desidratado do maracujá. Revista Brasileira de Zootecnia, v. 36, n. 05, p. 1489-1494, 2007.

CARVALHO, G. G. P. et al. Degradação ruminal de silagem de capim-elefante emurchecido ou com diferentes níveis de farelo de cacau. Revista Brasileira de Zootecnia, v. 37, n. 08, p. 1347-1354, 2008.

CHESSON, A.; GORDON, A. H.; LOMAX, J. A. Methylation analysis of mesophyll, epidermis and fibre cells - walls isolated from the leaves of perennial and Italian rygrass. Carbohydrate Research, v. 141, n. 01, p. 137-147, 1985.

CHIZZOTTI, M. L. et al. Casca de algodão em substituição parcial à silagem de capim- elefante para novilhos. 1. Consumo, degradabilidade e digestibilidade total e parcial. Revista Brasileira de Zootecnia, v. 34, n. 06, p. 2093-2102, 2005.

FERRARI JÚNIOR, E.; LAVEZZO, W. Qualidade da silagem de capim-elefante (Pennisetum purpureum Schum.) emurchecido ou acrescido de farelo de mandioca. Revista Brasileira de Zootecnia, v. 30, n. 05, p. 1424-1431, 2001.

FERREIRA, A. C. H. et al. Valor nutritivo das silagens de capim-elefante com diferentes níveis de subprodutos da indústria do suco de caju. Revista Brasileira de Zootecnia, v. 33, n. 06, p. 1380-1385, 2004.

FERREIRA, D. F. SISVAR - Sistema de Análise de Variância. Versão 3.04. Lavras: UFLA/DEX, 1999.

GONÇALVES, J. S. et al. Degradabilidade ruminal dos subprodutos agroindustriais do caju ("Anacardium occidentale" L.), graviola ("Anona muricata" L.), manga ("Mangifera indica" L.), e urucum ("Bixa orellana” L.) em ovinos. In: REUNIÃO ANUAL DA SBZ, 41., 2004, Campo Grande. Anais... Campo Grande, 2004. 1 CD-ROM. 
GONÇALVES, J. S. et al. Composição bromatológica e características fermentativas de silagens de capim-elefante (Pennisetum purpureum Schum.) cv. Roxo contendo níveis crescentes do subproduto da semente do urucum (Bixa orellana L.). Revista Ciência Agronômica, v. 37, n. 02, p. 228-234, 2006.

KATSUKI, P. A. et al. Cinética ruminal da degradação de nutrientes da silagem de milho em ambiente ruminal inoculado com diferentes aditivos. Revista Brasileira de Zootecnia, v. 35, n. 06, p. 2421-2426, 2006 .

MALAFAIA, P. A. M. et al. Determinação das frações que constituem os carboidratos totais e da cinética ruminal da fibra em detergente neutro de alguns alimentos para ruminantes. Revista Brasileira de Zootecnia, v. 27, n. 04, p. 790-796, 1998.

MARTINS, A. S. et al. Degradabilidade ruminal in situ da matéria seca e proteína bruta das silagens de milho e sorgo e de alguns alimentos concentrados. Revista Brasileira de Zootecnia, v. 28, n. 05, p. 1109-1117, 1999.

McDONALD, P. The Biochemistry of Silage. New York: John Willey \& Sons. 1981. 226 p.

MERTENS, D. R. Rate and extent of digestion. Chap. II. In: FORBES, J. M.; FRANCE, J. (Ed.) Quantitative aspects of ruminant digestion and metabolism. Cambridge: Commonwealth Agricultural Bureaux, Cambridge University Press, 1993. p. 13-51.

NEIVA, J. N. M. et al. Valor nutritivo de silagens de capimelefante enriquecidas com subproduto do processamento do maracujá. Revista Brasileira de Zootecnia, v. 35, n. 04, p. 1845-1851, 2006.

NOCEK, J. E. In situ and other methods to estimate ruminal protein and energy digestibility. Journal of Dairy Science, v. 71, n. 08, p. 2051-2069, 1988.

NOGUEIRA, D.; PAIVA, F. Urucum: opção natural, 2000. Disponível em: $<$ http://www.ruralnews.com.br $>$. Acesso em: 22 ago. 2006.

ØRSKOV, E. R.; McDONALD, P. The estimation of protein degradability in the rumen from incubation measurements weighed according torate of passage. Journal Agricultural Science, v. 92, p. 499-503, 1979.
PETIT, H. V.; TREMBLAY, G. H. In situ degradability of fresh grass and grass conserved under differente harvesting methods. Journal of Dairy Science, v. 75, n. 03, p. 774-781, 1992.

RÊGO, A. C. et al. Degradação da matéria seca, proteína bruta e fibra em detergente neutro de silagens de capim-elefante contendo pedúnculo de caju desidratado. Ciência Animal Brasileira, v. 10, n. 03, p. 735-744, 2009.

RÊGO, M. M. T. et al. Chemical and bromatological characteristics of elephant Grass silages with the addition of dried cashew stalk. Revista Brasileira de Zootecnia, v. 39, n. 02 , p. 255-261, 2010.

REZENDE, V. M. et al. Degradabilidade ruminal das silagens de capim-napier produzidas com diferentes níveis de farelo de "batata diversa". Revista Ciência Agrotecnologia, v. 31, n. 02, p. 485-491, 2007

SÁ, C. R. L. et al. Composição bromatológica e características fermentativas de silagens de capim elefante (Pennisetum purpureum Schum.) com níveis crescentes de adição do subproduto da Manga (Mangifera indica L.). Revista Ciência Agronômica, v. 38, n. 02, p. 199-203, 2007.

SAMPAIO, I. B. M. Experimental designs and modeling techniques in the study of roughage degradation in rumen and growth of ruminants. 1988. $214 \mathrm{f}$. Tese (Doutorado em Fisiologia) - University of Reading, 1988.

SILVA, D. J.; QUEIROZ. A. C. Análise de alimentos: métodos químicos e biológicos. 3. ed. Viçosa, MG.: Universidade Federal de Viçosa, 2002. 235 p.

SILVA, V. L. et al. Degradabilidade ruminal da matéria seca e da proteína bruta do subproduto de caju (Anacardium occidentale 1.) e do capim-elefante (Pennisetum purpureum) em ovinos. In: REUNIÃO ANUAL DA SBZ, 42., 2005, Goiânia. Anais... Goiânia. 2005. 1 CD-ROM.

VALADARES FILHO, S. C. Utilização da técnica in situ para a avaliação dos alimentos. In: SIMPÓSIO INTERNACIONAL DE PRODUÇÃO DE RUMINANTES, 31., 1994, Maringá. Anais... Maringá: SBZ, 1994. p. 95-118.

VILELA, G. L. et al. Degradabilidades "in situ" da matéria seca e da proteína bruta e proteína efetivamente degradada no rúmen, de vários alimentos. Revista Brasileira de Zootecnia, v. 23, n. 03, p. 342-351, 1994. 